\title{
1】 Das ovarielle Hyperstimulationssyndrom (OHSS) - eine radiologisch wenig bekannte Komplikation der hormonellen Infertilitäts- behandlung
}

Die hormonelle Stimulation der Ovarien ist ein anerkanntes Verfahren im Rahmen der Unfruchtbarkeitsbehandlung. Mit der Zunahme der Anwendungshäufigkeit dieser Behandlungsform nimmt entsprechend auch die Häufigkeit der möglichen Komplikationen zu, welche unter den Gynäkologen, die sich mit Unfruchtbarkeitsproblemen und deren Behandlung auseinandersetzen, gut be- kannt, Radiologen jedoch nicht gleichermaßen geläufig sind. Eine der möglichen Komplikationen ist das ovarielle Hyperstimulationssyndrom (OHSS). Dieses wird klinisch unterteilt in eine milde Form mit abdominellem Druckgefühl (Grad 1), Brechreiz und/oder Erbrechen (Grad 2) und in eine schwere, potenziell lebensbedrohliche Form mit Flüssigkeitsausschwitzungen in die Pe- 
ritonealhöhle und den Pleuraraum, Hämokonzentration und daraus resultierenden hämodynamischen und respiratorischen Problemen (Grad 4,5).

Wir berichten über eine Patientin mit schwerem OHSS nach Follikelstimulation mit der Absicht, an diese Differentialdiagnose zu erinnern, wann immer ein Spontanhydrothorax bei einer jungen, ansonsten gesunden Frau auftritt, die wegen Unfruchtbarkeit hormonell behandelt worden ist.

\section{Fallbeschreibung}

Eine 33 Jahre alte Frau wurde wegen primärer Unfruchtbarkeit mittels Follikel-Implantation und darauf folgender ovarieller Stimulation mit Choriongonadotropinen behandelt. 5 Tage nach Follikel-Implantation und Beginn der Gonadotropin-Stimulation wurde sie mit ausgeprägter Kurzatmigkeit (NYHA II-III) mit einer Atemfrequenz von $32 / \mathrm{min}$, Bauchschmerzen und Übelkeit vorstellig. Der Blutdruck betrug 130/70 mmHg, der Puls 130/min.

Die rechten Lungenunterfelder zeigten ein abgeschwächtes Klopf- und Atemgeräusch.

Eine Thorax-Übersichtsaufnahme zeigte einen ausgedehnten rechtsseitigen subpulmonalen Pleuraerguss (Abb.1a), welcher auch sonographisch bestätigt wurde (Abb. 1 b). Sonographisch zeigten sich ferner eine vernachlässigbare Menge freier Flüssigkeit im Douglas-Raum und multiple große $( \pm 5 \mathrm{~cm}$ Durchmesser) luteale Zysten in beiden Ovarien (Abb.2). Eine diagnostische und therapeutische Pleurapunktion förderte $1500 \mathrm{ml}$ klarer gelblicher pleuraler Flüssigkeit ohne Hinweis auf maligne Zellen, Mikroorganismen oder Pilze. Die Albuminkonzentration der Pleuraflüssigkeit lag bei $30 \mathrm{~g} / \mathrm{l}$ (Serum-Albumin $34 \mathrm{~g} / \mathrm{l}$ ), die totale Eiweißkonzentration bei $40 \mathrm{~g} / \mathrm{l}$ (Serum-Eiweiß $61 \mathrm{~g} / \mathrm{l}$ ) und die Glukosekonzentration bei 5,8 mmol/l, womit der Pleuraerguss mit einem Exsudat vereinbar war.

Eine zweite Pleurapunktion 3 Tage später mit Förderung weiterer $1500 \mathrm{ml}$ gleicher Flüssigkeit führte $\mathrm{zu}$ einer sofortigen Besserung der Kurzatmigkeit. Die Patientin wurde nach insgesamt 7 Tagen symptomfrei und mit normalisierten Blutwerten entlassen, eine Verlaufskontrolle 2 Wochen nach Entlassung zeigte keine erneute Ansammlung der pleuralen Flüssigkeit. Die hormonelle Stimulation ist sofort nach Eintritt ins Krankenhaus abgebrochen worden.

\section{Diskussion}

Das OHSS ist eine Komplikation nach hormoneller Stimulation der Ovarien mit Choriongonadotropinen und tritt mit einer Inzidenz zwischen 0,1 und $0,2 \%$ auf (Schenker et al., Fertil Steril, 61, 411-422, 1994). Am häufigsten kommt es hierbei zur Ausbildung von Aszites und damit vergesellschafteten gastrointestinalen Beschwerden und/ oder zu meist rechtsseitigen Pleuraergüssen (Abramov et al., Fertil Steril, 71, 645-651, 1999) und abhängig von der Ergussmenge zu daraus resultierenden respiratorischen Symptomen.

In seltenen Fällen, wie auch in dem von uns präsentierten Fall, kann der Aszites vollständig fehlen (Man et al., Eur Respir J, 10, 2425-6, 1997). Darum ist es umso wichtiger, im Kontext der genannten Befunde neben anderen Differenzialdiagnosen exsudativer Pleuraergüsse wie z.B. im Rahmen von Pleuropneumonien, Kollagenosen, Lungenembolien oder Tuberkulose auch an die seltene Möglichkeit des OHSS zu denken. Das Syndrom wird, wie anfangs erwähnt, in unterschiedliche Schweregrade eingeteilt, wobei die meisten Fälle einen leichten selbst limitierenden Verlauf nehmen mit spontaner Rückbildungstendenz.

Zur schweren Form gehört klassischerweise die Kombination von ausgedehntem Aszites, Pleuraerguss, Dyspnoe, hämodynamischer Instabilität, systolischem Blutdruck unter $100 \mathrm{~mm} / \mathrm{Hg}$, Oligurie, Anasarka und/oder eine ausgeprägte Hämokonzentration. Die kritische Form ist erreicht, wenn sich zu den vorgenannten Symptomen ein akutes Nierenversagen, ein ARDS, aufgepfropfte Pneumonien oder gar thromboembolische Ereignisse hinzugesellen (Abramov et al., Fertil Steril, 71, 645 - 651, 1999).

Im Falle einer zustande gekommenen Schwangerschaft in jedwelchem Stadium kann eine mütterliche Hypoxämie auf den Fötus ebenfalls verheerende Folgen haben.

Aus diesen Gründen ist es auch für Radiologen wichtig, das OHSS zu kennen, da es potenziell lebensgefährlich sein
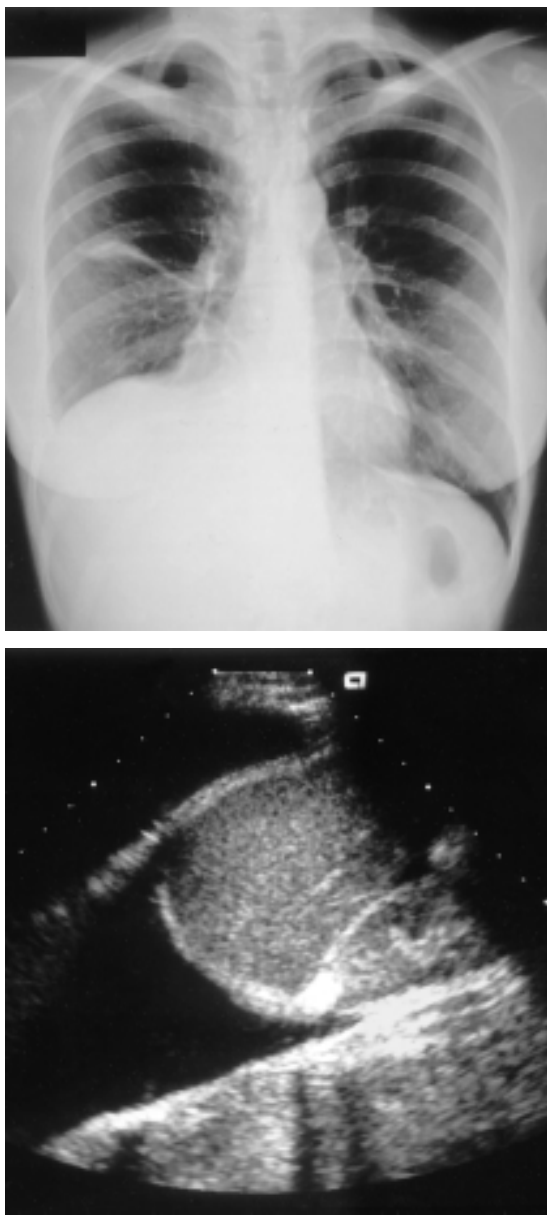

Abb.1 (a/b) Subpulmonaler Pleuraerguss rechts.

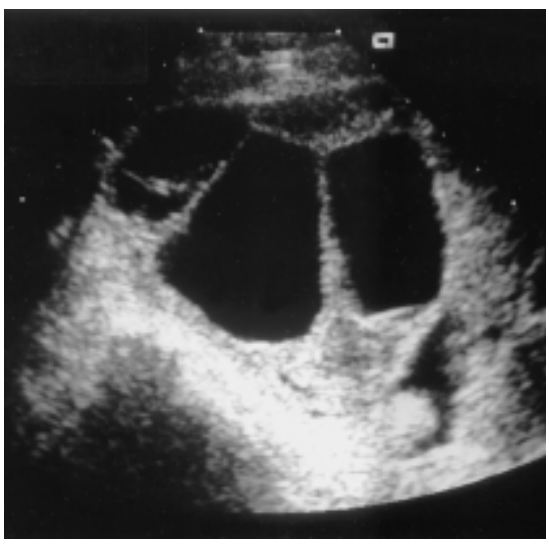

Abb. 2 Luteale Ovarialzysten.

kann und einer entsprechend zügigen Überwachung und Therapie zugeführt werden muss, was eine frühe Erkennung und richtige Deutung der Symptome und Befunde voraussetzt.

K. Steinke, M. Brutsche, W. Wiesner, Basel 